\title{
Influência de aspectos sociais e culturais na educação de crianças indígenas ${ }^{1}$ Cultural and social influences in the education of indigenous children
}

\author{
Sonia Grubits ${ }^{2}$ - Universidade Católica Dom Bosco, Campo Grande-MS, Brasil \\ Heloisa Bruna Grubits Freire ${ }^{3}$ - Universidade Católica Dom Bosco, Campo Grande-MS, Brasil \\ José Angel Vera Noriega ${ }^{4}$ - Centro de Investigação em Alimentação e Desenvolvimento AC., México
}

\section{Resumo}

Objetivamos verificar como características socioculturais e familiares influenciam na adaptação escolar de crianças guarani-kaiowá dos municípios Dourados e Caarapó, kadiwéu, da aldeia Alves de Barros na Bodoquena e terena de Córrego do Meio, município de Sidrolândia, em Mato Grosso do Sul, Brasil. Foram realizadas entrevistas e observações de crianças e pais dos referidos grupos. Observamos o diálogo e respeito mútuo na relação entre pais e filhos, evidenciado no tom sereno e suave com o qual as mães dirigem-se aos filhos. A curiosidade infantil não é reprimida, permitindo a exploração do ambiente, a participação em todas as atividades familiares, sem restrição, punição ou castigo. Porém no grupo terena, as mães conversam com as crianças, mas na segunda vez que elas desobedecem, levam palmadas ou "varinhadas" com vara verde, o que aponta para um exemplo de como a cultura vem se transformando pelo fácil acesso e contato com a sociedade nacional.

Palavras-chave: guarani-kaiowá; kadiwéu; terena, relações familiares, educação.

\begin{abstract}
The aim of this research was to verify how social-cultural and family characteristics influence in the adaptation of Indian children at school. The observed ethnic groups were the Guarani-Kaiowá (Caarapó and Dourados municipalities), the Kadiwéu (Alves de Barros) and Terena (Córrego do Meio), MS, Brazil. Interviews and observations were performed in those children and their parents. It was observed the dialog and the mutual respect in the relations, evidenced in a serene tone with which mothers addressed to their children. Children's curiosity is not repressed, as well as the participation in all of the family's activities without restriction or punishment. However, in the Terena's group, mothers at first talk to their children, and at second if they disobey again, they get slaps or get bitten by sticks. That behavior points out to an example of how culture is changing by the easy access with the national society.

Keywords: guarani-kaiowá; kadiwéu; terena; family life; education

\section{INTRODUÇÃO}

Nossa experiência em pesquisas com populações indígenas, desde o final da década de 80 buscando o entendimento dos processos de construção da identidade em diferentes grupos de Mato Grosso e Mato Grosso do Sul propiciou a emergência de diversos temas importantes na área de educação, saúde, políticas públicas e ética, entre outros. Em trabalhos de campo

com os grupos guarani dos municípios de Caarapó e Dourados e kadiwéu da Aldeia Alves de Barros, na região da Bodoquena, notamos que as crianças eram tranquilas, alegres, disciplinadas e acolhiam bem os visitantes. Relatos de educadores, outros pesquisadores e profissionais que trabalham e estudam grupos indígenas também confirmam tais observações.

\footnotetext{
Apoio do CNPq, Fundect e FUNASA.

${ }^{2}$ Doutora com status de pós-doutora em Semiótica por Paris 8 - Sorbonne, França, pós doutora e doutora em Saúde Mental pela Faculdade de Ciências Médicas da UNICAMP, Mestrado em Psicologia Social pela PUCSP, Psicóloga pela PUCRJ. Formada em Comunicações pela UFRJ, professora, pesquisadora e coordenadora do Programa de Mestrado em Psicologia da Universidade Católica Dom Bosco, UCDB, MS, Brasil e bolsista de produtividade pesquisa do CNPq. E-mail: sgrubits@uol.com.br. Av. Mato Grosso, n. 759, Centro, Campo Grande/MS, Brasil, Cep 79002 - 231, Tel./Fax: (55) (67) 33823631

${ }^{3}$ Doutora em Saúde Mental pela Faculdade de Ciências Médicas da UNICAMP, mestre em Psicologia, psicóloga pela UCDB, professora, pesquisadora do Programa de Mestrado em Psicologia da Universidade Católica Dom Bosco, MS, Brasil. E-mail: freirejb@terra.com.br. Av. Mato Grosso, n. 759, Centro, Campo Grande/MS, Brasil, Cep 79002 - 231, Tel./Fax: (55) (67) 33823631

${ }^{4}$ Professor pesquisador na área de Desenvolvimento Regional, Centro de Investigação em Alimentação e Desenvolvimento A.C., México. E-mail: avera@cascabel.ciad.mx. Apartado Postal 1735, Carretera a la Victoria km. 0.6, Hermosillo, Sonora, México. C.P.83000, Tel.: (662) $289-24-00$ Ext. 317, Fax: (662) $280-00-55$.
}

Psico-Usf, v. 14, n. 3, p. 365-374, Setembro/Dezembro 2009 
Entendemos que esta característica comum às comunidades indígenas de Mato Grosso e Mato Grosso do Sul são consequência de suas normas, crenças, bem como da representação social da infância, tendo como recorte as relações e estruturas familiares, o estilo de educação e a sua repercussão na formação da criança. Posteriormente, em trabalhos de campo semelhantes em outro projeto com os terena de Córrego do Meio, município de Sidrolândia, notamos algumas alterações no sistema educacional, acompanhando uma tendência maior e mais acelerada de mudanças nas tradições e cultura.

Por outro lado, "na atualidade, a indisciplina escolar é um dos temas que mais afligem professores, técnicos e pais na sociedade nacional, tanto no que se refere à clareza quanto ao consenso sobre indisciplina, quanto ao porquê das crianças não aceitarem regras e limites e, de um modo geral, terem um comportamento grupal de muita inquietação, denominado usualmente de "bagunça" (Lino, 2006 p.16).

A questão da indisciplina em sala de aula de escolas de nossa sociedade é um dos temas que atualmente mais mobilizam professores, técnicos e pais, desde a educação infantil ao ensino médio, fato que não é evidenciado em escolas indígenas. Segundo Rego (1996), entende-se por disciplina, a ordem, o respeito, a obediência às leis, porém, supõe-se que a criança já tenha adquirido anteriormente o conhecimento de valores éticos como: entendimento de regras, partilha de responsabilidades, cooperação, reciprocidade, solidariedade e ainda o reconhecimento dos direitos do outro, sem o qual fica impossível a convivência em grupo. Esses valores têm origem na família, ou seja, na socialização primária.

Ferreira (2007) informa que o desenvolvimento individual está relacionado a fatores genético-individuais, experiências individuais precoces e, principalmente, à relação de comportamentos inadaptados às características das crianças, às práticas parentais, à história de interação familiar e à situação escolar. Comenta sobre a importância da complementação escola e família para o desenvolvimento infantil:

A escola completa o quadro das influências mais significativas sobre o comportamento infantil e contribui de diversos modos para a formação do indivíduo por meio de desenvolvimento de comportamentos, habilidades e valores, etc. Os dois principais ambientes na vida da criança (o doméstico e o escolar) concorrem para que o resultado final seja percebido pelos pais e educadores como comportamento adaptativo ou desadaptativo, com o "bom" comportamento ou "mau" comportamento (Ferreira, 2007 p. 16).
Assim, estudar a escola a partir da análise de seu cotidiano é compreender a ação de cada sujeito que nela atua, entendendo essa realidade articulada à realidade da sociedade em que esse sujeito vive. Pretendemos, portanto, refletir tal situação com embasamento em trabalhos de autores clássicos e estudos mais atuais (Berger \& Luckmann, 1985; Cabrera, 2006; Grubits \& Darrault-Harris, 2003; Lino, 2006; Mangolim, 1999; Viveiros de Castro, 1986; Vygotsky, 1987; entre outros).

Para localizarmos nosso referencial quanto à adaptação escolar e sua relação com a educação e cultura familiar, apresentaremos uma breve revisão bibliográfica sobre educação, seguida de aspectos relevantes das culturas guarani/kaiowá, kadiwéu e terena. Finalmente, apresentaremos resultados de análises de entrevistas e observações realizadas durante o trabalho de campo.

\section{A IMPORTÂNCIA DA FAMÍLIA NA SOCIALIZAÇÃO INFANTIL}

Tratar sobre adaptação escolar e educação implica uma reflexão sobre a família. A família, primeiro grupo social do qual a criança faz parte, exerce um papel fundamental na sociedade na qual está inserida, tendo a função da criação dos filhos. Sua função social é transmitir valores culturais e ideológicos, as idéias relevantes em determinado momento histórico, educando as novas gerações segundo padrões dominantes e hegemônicos de valores e de conduta.

É responsável pela sobrevivência física e psíquica das crianças, constituindo-se no primeiro grupo de mediação do indivíduo. É na família que ocorrem os primeiros aprendizados dos hábitos e costumes da cultura, lugar onde se concretiza, em primeira instância, o exercício dos direitos da criança e do adolescente, o direito aos cuidados essenciais para seu crescimento e desenvolvimento físico, psíquico e social.

Segundo Hutz (2005), quando os pais oferecem aos filhos um ambiente incentivador e protetor, representado por afeto e atenção, acrescidos de exigências e restrições, constituem a base necessária para a socialização. A família é, então, a primeira instituição na qual a criança será inserida após seu nascimento e é lá que receberá todo o suporte para fazer parte da sociedade.

Além da função biológica e de organização da base emocional, a família também tem uma função ideológica. Segundo Reis (1984 p. 104):

Para entendermos mais profundamente como a família cumpre suas funções de agente de reprodução ideológica é necessário 
voltarmos a atenção para o seu funcionamento interno. Nesta perspectiva, podemos observar o que mais a diferencia de outros grupos: ela é o lócus da estruturação da vida psíquica. É a maneira peculiar com que a família organiza a vida emocional de seus membros que lhe permite transformar a ideologia dominante em uma visão de mundo, em um código de condutas e de valores que serão assumidos mais tarde pelos indivíduos.

A autora cita conceitos desenvolvidos por Mark Pôster (1979), pois para ele a família é o lugar onde se forma a estrutura psíquica e onde a experiência se caracteriza, em primeiro lugar, por padrões emocionais. A função de socialização está implícita nesta definição, mas a família não está sendo conceitualizada primordialmente como uma instituição investida na função de socialização. Em vez disso, é considerada a localização social onde a estrutura psíquica é proeminente de um modo decisivo.

Assim, de acordo com os parâmetros da psicologia social, a instituição denominada família é responsável pela socialização primária, a primeira socialização que o individuo experimenta na infância e em virtude da qual se torna membro da sociedade.

Ainda segundo Reis (1984 p. 104):

É na família que os indivíduos são educados para que venham a continuar biológica e socialmente a estrutura familiar. Ao realizar seu projeto de reprodução social, a família participa do mesmo projeto global, referente à sociedade na qual está inserida. É por isso que ela também ensina a seus membros como se comportar fora das relações familiares em toda e qualquer situação. A família é, pois, a formadora do cidadão.

Para Berger e Luckmann (1985), a sociedade, enquanto formadora de cidadãos, deve ser entendida como uma realidade tanto objetiva quanto subjetiva, ou seja, um processo dialético, em que ao mesmo tempo em que o homem é produto desse meio é também seu produtor, e tudo isso se processa em três momentos distintos, a exteriorização, a objetivação e a interiorização. Esses três momentos não devem ser pensados isoladamente, mas em decorrência de um processo simultâneo, cujo ponto inicial é a interiorização, ou seja, a apreensão e interpretação dos acontecimentos para um indivíduo em uma dada sociedade.

A apreensão de interpretação referida por Berger e Luckmann (1985) começa com o fato do indivíduo "assumir" o mundo no qual os outros já vivem, o que constitui um processo original que irá variar de pessoa para pessoa, e este mundo, uma vez reconhecido, poderá ser modificado à maneira de cada um. Segundo os autores, a socialização primária, nos primeiros anos de vida em contato com a própria família, ocorre em circunstâncias carregadas de afeto. A criança identifica-se com os outros pela multiplicidade de modos emocionais, porém a interiorização só ocorrerá se for precedida pela identificação é por meio desta que a criança torna-se capaz de identificar a si mesma, absorvendo os papéis e as atitudes dos outros, tornando-os seus.

Já na socialização secundária, o indivíduo estabelece suas relações, em outras instituições, como, por exemplo, a escola, a partir de suas idiossincrasias, dependendo dos conteúdos específicos já interiorizados na socialização primária. "Na socialização primária, por conseguinte, é construído o primeiro mundo do indivíduo" (Berger \& Luckmann, 1985 p. 182).

Diante dessas premissas, considera-se que a educação recebida na família cumpre um papel primordial na constituição do indivíduo cultural. Tem-se o conhecimento de que a mãe é muito importante para a criança: é o primeiro olhar, o primeiro contato, é quem cuida, ampara, alimenta. A família, de um modo geral, também desempenha esse papel, inicialmente por meio do pai, e depois dos outros membros, como: irmãos, tios, avós etc. Mas é a mãe ou quem desempenha esse papel, quem inicialmente acolhe a criança, cuida dela e permite a entrada do "outro" nessa relação. A socialização primária termina quando for interiorizado o "outro generalizado", possibilitando ao indivíduo tornar-se membro efetivo da sociedade e possuir subjetivamente uma personalidade e um mundo. Assim, inicia-se a socialização secundária.

Segundo Reis (1984), a família tem sido foco de atenção de vários estudiosos, e apesar de todas as críticas em relação a esta instituição, não pode ser negada sua importância no nível das relações sociais, pois é na família, entre indivíduo e a sociedade, que aprendemos a perceber o mundo que nos cerca. Cabe à família, como vimos, o processo de socialização primária, o qual já vimos, e que carregamos vida afora, e particularmente, a formação de nossa identidade social.

Sua formação na consciência significa que o indivíduo identifica-se agora não somente com os outros concretos, mas com uma generalidade de outros, isto é, com uma sociedade. "Somente em virtude desta identificação de generalidade sua identificação consigo mesmo alcança estabilidade e continuidade" (Mead, 1959 apud Berger \& Luckmann, 1985 p. 178). No processo de socialização a criança tem a possibilidade de adquirir conhecimento dos valores, normas, 
costumes pessoais, instituições, símbolos sociais, como também a aprendizagem da linguagem e a aquisição de condutas sociais desejadas ou não (López, 1995).

Todas essas considerações denotam que os aspectos abordados nesta pesquisa, em relação à socialização primária da criança, condizem com a interiorização de alguns aspectos educacionais na família, que posteriormente deverão ser generalizados por esta mesma criança em ambiente escolar, ou seja, na socialização secundária. A socialização secundária é a interiorização de submundos institucionais ou com base nas instituições. É a aquisição do conhecimento de funções específicas observadas direta ou indiretamente na divisão do trabalho, ou melhor, é a socialização encontrada no contato com instituições fora do ambiente familiar. Esses submundos são realidades caracterizadas por componentes normativos, afetivos e cognoscitivos, sendo este o momento em que se concretiza a aprendizagem. Portanto, a socialização secundária é realizada também na escola, podendo até ser denominada como o segundo grupo social no qual a criança é inserida.

De acordo com Vygotsky (1987), autor que aborda a formação do psiquismo humano em seu contexto histórico-cultural, as características de cada indivíduo são formadas a partir de inúmeras e constantes interações do indivíduo com o meio, compreendido como contexto físico e social, que inclui as dimensões interpessoal e cultural. Logo, desde o nascimento e durante toda a vida, este mesmo indivíduo estabelece trocas recíprocas com o meio, já que ao mesmo tempo em que internaliza as formas culturais, as transforma e intervém no universo que o cerca.

Para o autor acima citado, de tradição sociointeracionista, os processos psicológicos originam-se nas relações interpessoais e se desenvolvem ao longo do processo de internalização de formas culturais de comportamento. Ele chama atenção para o importante papel mediador exercido por outras pessoas nos processos de formação dos conhecimentos, habilidades de raciocínio e procedimentos comportamentais de cada indivíduo.

Vygotsky (1987) explica que é por intermédio dessas mediações, encontradas inicialmente no meio familiar, que o humano, até então imaturo, apropriase de forma ativa dos modos de funcionamento psicológico, do comportamento e da cultura, ou melhor, do patrimônio da história da humanidade e de seu grupo social. Dessa maneira, ao internalizar as experiências fornecidas pela cultura familiar e social, a criança reconstrói individualmente os modos de ação realizados externamente e aprende a organizar os próprios processos mentais, a controlar e dirigir seu comportamento e a agir no meio.
Portanto, na socialização secundária não ocorrerão identificações como na socialização primária, mas farão parte da vida do indivíduo como os muitos grupos a que este indivíduo pertence, como: a igreja, a escola, o trabalho, a comunidade, entre outros, e dessa forma, o processo de socialização é ininterrupto, ocorrendo consequentemente à formação da identidade do indivíduo.

Nas sociedades modernas a escola acolhe a criança, que fica privada do contato direto com o adulto (fora da escola) durante parte do dia, geralmente durante manhã e/ou tarde e algumas vezes em regime de internato ou semi-internato, devido a diferentes fatores como atividades profissionais dos pais. Não encontramos tal situação nas sociedades indígenas estudadas, pois mesmo com o surgimento das escolas nas aldeias, notamos maior flexibilidade nos deslocamentos e a criança tem liberdade para permanecer junto aos adultos, ouvindo as conversas em família ou mesmo nas reuniões promovidas pelos grupos, como conselho da comunidade, grupo de mulheres, entre outros. Cabe ressaltar, que nos trabalhos com os terena estamos começando a perceber algumas mudanças neste estilo de educação.

Meliá (1979) cita que uma dupla atitude aparentemente contraditória chama a atenção do não-índio ao observar uma sociedade indígena: as crianças gozam de uma grande liberdade de ação, "fazendo o que querem", sem que os adultos se imponham com admoestações ou proibições; nota-se que essas crianças não dão motivos de aborrecimento aos pais ou a outros membros da comunidade. $\mathrm{O}$ adulto considera a criança na sociedade indígena com muito respeito, carinho e seriedade. O carinho que os pais têm com as crianças, o modo de falar e de persuadi-la é extremamente respeitoso.

\section{OS GUARANI, KADIWÉU E TERENA}

Um entendimento das reações e das relações da criança indígena nas escolas das aldeias demanda um conhecimento das principais características das etnias em questão e principalmente a percepção das diferenças na organização social e cultural existente entre elas. Cabe ressaltar que, apesar das diferenças significativas, as observações sobre a criança na escola e contexto familiar na educação são muito semelhantes.

Sobre os guarani, a extensão das diferenças entre as nações indígenas brasileiras é expressa por Viveiros de Castro (1986 p. 29) quando afirma: “[...] as sociedades gê e tupi guarani ${ }^{1}$ parecem estar em oposição polar, ao longo de um continuum virtual das

\footnotetext{
$\overline{1}$ Tupi é um dos ramos da sociedade Guarani com estrutura social e língua semelhantes aos demais.
} 
diversas formações socioculturais dos povos sul-americanos, para as mais variáveis que decidi note-se bem privilegiar em meu trabalho". Os tupi-guarani, para Viveiros de Castro (1986), definiam-se num "vir-aser" num tornar-se o outro, de forma diversa da pessoa gê-bororo, que subjuga a diferença à identidade. Ainda segundo o autor, a dinâmica subjacente ao movimento em direção ao outro pode ser identificada na solução antropofágica dos tupiguarani. A identidade, segundo o autor, seria "antidialética". Esses povos apresentam uma inversão da representação tradicional da sociedade primitiva, feita pela antropologia.

A cosmologia do grupo passa por conceitos básicos como deus, ser humano e inimigo. O que está fora da sociedade é que a ordena e orienta. Seu modelo cosmológico configura-se a partir do sistema de alma, nome, morte, canibalismo e canto. Além disso, apresenta uma enorme flexibilidade sociológica, indiferenciação interna associada a um complexo de relações individualizadas com o mundo espiritual. Esta posição estratégica para a construção da pessoa gera aquilo que foi chamado por Viveiros de Castro (1986) de individualismo (Grubits \& Darrault-Harris, 2001).

Sua concepção da alma humana é a chave do seu sistema religioso e comanda a vida social desta sociedade. A predominância da religião e da relação com a morte, subjacente na noção de alma ou na teoria da pessoa, constituem um ponto de apoio essencial para a compreensão de sua organização social. Assim, a pessoa ocupa um espaço virtual entre a natureza e sobrenatureza, ou seja, um elemento paradoxal que conectaria e separaria, circulando como espaço vazio entre domínios e formas do extrassocial. "É neste sentido que a Pessoa tupi-guarani é um entre (um entre dois) e não um ente" (Viveiros de Castro, 1986 p. 104). Outro aspecto relevante para o entendimento de sua peculiar cultura e organização social é que, apesar da extensa amplitude do seu território, no passado, sempre existiu uma significativa homogeneidade linguística dos seus dialetos e de sua cosmologia.

Segundo estudos e observações de Schaden (1974), a criança guarani é notavelmente independente. O guarani não acredita na conveniência e eficácia de métodos educativos, a não ser a título excepcional ou por via mágica. As crianças guarani têm total liberdade de convivência com os adultos. Tal fato talvez as torne mais espontâneas e francas quando em contato com estranhos. Essa influência pode ser observada também na ausência de brinquedos, pois as brincadeiras se concentram na imitação de atividades dos adultos.

O guarani respeita a personalidade e a vontade individual infantil, não ocorrendo a repressão no processo educativo. Assim, na infância, o Guarani segundo Schaden (1974), não aprende a dominar-se e a contrariar as suas inclinações e o seu temperamento.

Para os Guarani, a alma já nasce com um potencial e qualidades e eles não se preocupam, por essa razão, com o desenvolvimento da natureza psíquica. Schaden (1974 p.62) relata que os nandéva, "não ensinam as rezas às crianças, porque, sendo individuais, são mandadas diretamente pelas divindades. Desde a mais tenra infância, cada nandéva participa das cerimônias da família e de toda a comunidade, aprendendo, assim, sem esforço, tudo o que faz parte do patrimônio grupal; ao mesmo tempo, fica aguardando que lhe seja enviada a sua própria reza, que receberá em sonho. $\mathrm{O}$ mesmo se dá entre os mbua, onde cada qual conhece, à força de ouvi-las sempre, as rezas de todos os companheiros".

A base da organização social dos guarani é a família-grande; a criança que cresce nessa família aprende a fixar ou focalizar suas emoções ou expectativas de recompensa e punição em poucas ou determinadas pessoas, pois muitos adultos as punem ou recompensam.

Meliá (1979) informa que o sentido da educação guarani-kaiowá, é sobretudo moral e espiritual, e, portanto, deve conservar o 'modo de ser guarani'. Sendo assim, a educação está orientada a alcançar a perfeição com a reza, a não-violência e visão "teológica" do mundo, o que para o Guarani só pode ser alcançado por meio da comunidade e da inspiração.

Os kadiwéu, um grupo menor, ocupam, há mais de dois séculos, uma área situada entre a serra da Bodoquena a leste, Paraguai a sudoeste e, ao sul, o pantanal mato-grossense, na parte oeste do estado de Mato Grosso do Sul. Ressalte-se que a referida área é de difícil acesso. A língua kadiwéu é a única representante da família guaicuru a leste do rio Paraguai. As línguas da família guaicuru são faladas por povos tipicamente chaquenhos, habitantes do Chaco paraguaio e argentino. As afinidades entre os vários dialetos dessa família são muito próximas, já sendo observadas pelos jesuítas no século XVII.

A questão das relações intertribais sempre foi significativa para o entendimento do funcionamento e dinamismo da sociedade Kadiwéu, sendo o que justifica e estabelece a pauta dessas relações. O mito de criação e diferenciação da humanidade evidencia o caráter das relações intertribais assimétricas e contextualiza o surgimento dos ekalai, os não-índios, e define o comportamento dos kadiwéu, enquanto guerreiros. Siqueira Jr. (1987) relata que versões e variantes mais recentes já acrescentam o tema território como atributo diferenciador. 
A literatura histórica existente sobre esse grupo destaca sua estrutura social, baseada numa organização estratificada em castas: os nobres ou senhores, os guerreiros e cativos. Esses últimos eram capturados durante as guerras intertribais e integrados na sociedade guaicuru, recebendo determinadas atribuições. Atualmente, não existem mais as guerras intertribais e a captura de cativos, mas termos específicos são empregados para indicar relações de consanguinidade e afinidade, relações socialmente determinadas, como as que se estabelecem entre descendentes de senhores e cativos, e, entre padrinhos e afilhados, adotados da população regional.

Os kadiwéu praticam ainda rituais de iniciação e os relacionados à morte e ao luto, atividades rituais realizadas nas festas do Bate-Pau (também realizadas pelos terena, um pouco modificadas) e do Bobo, que, por sua vez, ocorrem principalmente no dia do índio e ocasionalmente em outras datas festivas. A Festa da Moça constitui-se no ritual de iniciação feminina, realizado quando a adolescente kadiwéu tem sua primeira menstruação. Apesar de a atividade xamanística ter perdido muito de sua importância na vida desse grupo, o reduzido número de nidjienigi (xamãs), também chamados padres, existentes atualmente na reserva indígena kadiwéu conserva certo prestígio. Uma das principais atividades, a de curador, sofre a concorrência direta da assistência médica prestada pelos missionários evangélicos ou da Fundação Nacional de Saúde FUNASA, recorrendo os kadiwéu frequentemente às duas práticas (Grubits \& Darrault-Harris, 2003).

A economia kadiwéu se organiza hoje em dia, principalmente, em torno da obtenção dos recursos provenientes de arrendamento dos pastos, atividades agrícolas, e criação de bovinos e equinos e, em menor escala, de caça, pesca e coleta, além da realização de empreitadas e da venda da força de trabalho nas fazendas vizinhas à reserva e junto aos próprios arrendatários. Todas essas tarefas são basicamente masculinas, excetuando-se a coleta. As mulheres são as principais produtoras de artesanato para venda, gerando recursos razoáveis para economia familiar. Nossos estudos indicaram duas questões importantes para o grupo kadiwéu: as questões de gênero, principalmente nos aspectos referentes à divisão de trabalho e, a outra, a importância da arte, em especial, os desenhos, os traçados abstratos, indicando a marca de cada grupo familiar, com a preservação das técnicas originais e naturais no preparo e elaboração das peças de cerâmica.

Os terena, juntamente com o grupo guarani/ kaiowá, constituem a maior nação indígena em Mato Grosso do Sul, com cerca de vinte e cinco mil pessoas, de um total de cerca de cinquenta mil que habitam o estado. Além desses grupos, encontramos também os kadiwéu, acima citados, ofaié e guató, kinikinawa, porém com populações bem menores.

Os terena pertencem ao povo aruak e vieram pelo alto Rio Negro, sendo as hipóteses levantadas sobre sua origem de que partiram das planícies colombianas e venezuelanas. Recentemente, surgiu a hipótese da origem no Equador. Da mesma forma que outros grupos, os terena entraram no território sulmato-grossense a partir do século XVIII. Estão atualmente assentados em doze reservas, num total de cerca de dezenove mil e dezessete hectares de terra, localizados principalmente na Bacia do Rio Miranda. Existe também um contingente vivendo em fazendas e na cidade, denominados desaldeados, e numa aldeia urbana, em Campo Grande, atualmente conhecida como Conjunto Marçal de Souza (Cabrera, 2006).

Os terena, sobretudo aqueles residentes nas aldeias mais "tradicionais", como Cachoeirinha e Bananal, apesar do contato regular com a sociedade nacional, utilizam os poderes dos seus "porangueiros", ou curadores, que são os xamãs, denominados pelos terena: koixomuneti. Tais curandeiros são responsáveis pela cura de doenças e possuem o poder de descobrir feitiço que terceiros podem ter colocado no doente, causando sua morte (Ladeira \& Azanha, 2004).

Ladeira e Lazanha (2004) relatam o mito de origem do povo terena, sobre um herói civilizador duplo que tem uma parte "gêmea" que age como um anti-herói, denominado Yurikoyuvakái que tirou-os de debaixo da terra e ensinou-lhes o uso do fogo e das ferramentas agrícolas. $\mathrm{O}$ mito de origem é passado de geração a geração em algumas comunidade, em geral pelos mais velhos.

Essa duplicidade fundamenta o comportamento dos membros das metades xumonó, os gozadores, "bravos" e sukirikionó, sérios e mansos que ainda são presentes em muitos aspectos da vida social e cerimonial terena. Segundo Mangolim (1999), as religiões chamadas "cristãs" são aceitas quando afirmam os princípios básicos da cultura terena, mas também amedrontam com as idéias de que fora do cristianismo não há salvação.

Um elemento importante para desenvolvermos uma proposta de pesquisa na área de psicologia social é a identificação dos terena como um povo ligado à agricultura, de índole pacífica, muitas vezes submetidos por outras nações e aceitando com facilidade as regras do dominador. Esse fato é apontado como causa da eventual descaracterização do grupo, apesar de indicações de que os Terena ainda são capazes de manter elementos culturais profundos que lhes dão coesão (Mangolim, 1999). No final da década de 90, 
este quadro começa a se transformar, com os movimentos políticos envolvendo a retomada de terras que pertenciam no passado aos terena, além de outras reivindicações na área de educação e saúde.

Sempre demonstraram disposição para contatos pacíficos com a população da região, participando da comercialização de produtos agrícolas, principalmente milho, mandioca, batata-doce, abóbora etc. Também no artesanato trabalham com a cerâmica, basicamente atividade feminina, ficando para os homens a cestaria, caça e pesca. Tiveram como fato significativo na sua história, a atuação na guerra do Paraguai, a partir do que surgiu a dependência do trabalho na região, como mão-de-obra dos fazendeiros. Participaram da construção da linha telegráfica no extremo oeste do país, comandada pelo Mal. Rondon, que demarcou suas reservas para reagrupálos. Além disso, muitos índios terena trabalharam na construção da estrada de ferro Noroeste do Brasil. Atualmente, observou-se que sua aproximação com os moradores das regiões onde estão assentados é cada vez maior, buscando trabalho na comunidade (Mangolim, 1999).

\section{OBJETIVOS E PROCEDIMENTOS}

Nos trabalhos de campo com as três etnias buscamos identificar quais os aspectos culturais relacionados com as atividades infantis, normas e crenças, contidos nos processos de socialização primário e secundário. Para tanto, caracterizamos a representação social da infância, reunimos subsídios e informações relevantes, objetivando contribuir para discussões e reflexões sobre o ajustamento da criança indígena e não-indígena ao ambiente escolar.

Mediante o material colhido, fizemos uma análise qualitativa de relatos e falas agrupados por temas selecionados, visando entender e interpretar a significação dos fenômenos em foco, assim como determinar por meio dos significados como se dá o processo de formação da personalidade e da educação das crianças indígenas guarani-kaiowá, kadiwéu e terena e suas especificidades culturais, reveladas no posterior comportamento em ambiente escolar. Os temas para análise foram selecionados visando contemplar os objetivos propostos, e para a interpretação dos dados foram utilizados preceitos de compreensão da psicologia social, de estudos sobre estas populações indígenas, associando a isso discussões sobre a cultura local.

\section{AS ANÁLISES}

As observações, entrevistas e conversas informais registradas nos trabalhos de campo durantes as pesquisas com os três grupos em questão apontaram para o diálogo como a principal forma de educar uma criança. A conversa, o uso de conselhos e a não-punição física foram observados na educação indígena, confirmando dados da literatura. Percebemos, porém que os terena tendem, em comparação aos guarani/kaiowá e kadiwéu, a algumas formas de controle que não correspondem aos padrões indígenas, de acordo com os autores citados e informações de pesquisadores e técnicos que mantêm contatos frequentes com referidas etnias.

Podemos ilustrar tais situações com falas e depoimentos de mães e pais que participaram das pesquisas e nossas observações. Em visitas à reserva guarani/kaiowá, na Escola Municipal Indígena do Agustinho, em Dourados, constatamos como as crianças tinham bem internalizadas as normas e regras de convivência. Em nenhum momento mostraram-se apáticas aos jogos e brincadeiras; ao contrário, riam, faziam gracejos, brincavam umas com as outras, porém a um pedido de silêncio do professor, logo obedeciam (Lino, 2006).

Tal fato reflete como a família organiza a vida emocional de seus membros, o que lhes permite transformar a ideologia dominante em uma visão de mundo, em um código de condutas e de valores que serão assumidos mais tarde pelos indivíduos, como foi analisado por Reis (1984) tendo, portanto, como conseqüência, o comportamento adaptado das crianças indígenas em sala de aula.

Assim também, de acordo com Meliá (1979) que identifica uma dupla atitude aparentemente contraditória para os não-índios ao observar um grupo indígena, pois segundo ele as crianças gozam de uma grande liberdade de ação sem que os adultos se imponham com repreensões ou proibições. Os pais e outros membros da comunidade reagem aos comportamentos infantis, que os não-índios denominam travessuras ou erros e falhas passíveis de correção e punição, entendendo que são características normais e próprias do desenvolvimento infantil. Dessa maneira, as crianças não dão motivos de aborrecimento aos pais ou a outros membros da comunidade.

Para ilustrar tais conclusões temos informações recorrentes de pais e mães guarani-kaiowá, como no caso dos fragmentos abaixo relacionados. ${ }^{2}$

Eu aconselho, né? Aconselho primeiro para depois
perguntar. Tem que aconselhar para depois per-
guntar... já foi feito mesmo né? Você pergunta e ele
já conta... o caminho épara o dia de amanhã; o que
jápassou, já passou por que ele vai crescer, e é assim

$\overline{2}$ Integrante do grupo de pesquisa com crianças Guarani/Kaiowá, Lino (2006: 82). 
que nós carregamos a familia, casado também é tudo assim, aconselhar, perguntar para depois falar qual é o caminho certo... tem dois caminhos para a gente seguir desde criança, o bem e o mal, então nós já falamos isso para ele, depois de sete anos ele já escuta a voz do pai e da mãe. (FE-1, pai)

Para educar? Eu acho que é... Para educar não dá para bater. É só conversar mesmo, conversar muito. Para educar mesmo as crianças. Para bater, ai machuca e sobe na cabeça e é pior para as crianças e não adianta, por isso tem que só conversar e pôr a criança no caminho [...]. (FE-3)

Oh! isso ai tem que ser com a palavra... que não prejudica. (FE-1)

Tem uma diferença, os brancos têm a cabeça que estuda, mas nas idéias são fracos, o indio não tem estudo, mas nas idéias tem mais atenção, aconselha a familia, épor aí, só isso que eu sei. (FE-1, pai)

Tais afirmações podem ser relacionadas ao "modo de ser guarani”". O sentido da educação é moral e espiritual, orientada a alcançar a perfeição por meio da reza, da não violência e da visão "teológica" do mundo, o que para o guarani é alcançado por meio da comunidade e da inspiração, segundo Meliá (1979).

Indicam também a "flexibilidade sociológica, indiferenciação interna associada a um complexo de relações individualizadas com o mundo espiritual" e individualismo, segundo Viveiros de Castro (1986). Lembramos que o autor pontua a predominância da religião e da relação com a morte, subjacente na noção de alma ou na teoria da pessoa, que constitui um ponto de apoio essencial para a compreensão de sua organização social.

Schaden (1974), analisando a educação infantil guarani, relata que o adulto respeita a personalidade e a vontade individual da criança, que não aprende a dominar-se e a contrariar as suas inclinações e o seu temperamento, não ocorrendo, portanto, a repressão no processo educativo.

Os fragmentos seguintes são ilustrações muito significativas da educação familiar da cultura guarani/kaiowá, ainda de acordo com os autores acima citados:

Criança é, é para ficar no lugar do pai, cresce, não sabe o dia, o pai é chamado... o pai sobe e a criança fica e o conselho é levado para frente, e a criança fica relembrando o que pai falava para ela [...]. (FE-1)

Eu acho que é a família que ensina as crianças, acho que criança nasce boazinha mesmo né, depois fica pegando o costume para ficar assim, teimosa, onde a família põe no caminho, né! (FE-3)
As crianças brincam de imitar os adultos e seu brinquedo é, de acordo com o sexo, o instrumento de trabalho do pai ou da mãe, bem como seus comportamentos, o que permite aos pais observar, aconselhar e "pôr no caminho". Estas cenas são comuns a qualquer visitante em uma reserva indígena e inclusive na reserva indígena de Dourados, conforme fragmento de entrevista que segue:

Eles brincando assim só, nem na bola, nem nada, só brincando assim com outro. (FE-2)

Quanto ao grupo kadiwéu da aldeia Alves de Barros, também observamos muito acolhimento familiar, com parentes ou os pais junto às crianças, além do hábito da menina permanecer com a mãe ceramista, brincando e assim adquirindo conhecimentos sobre a tarefa materna. Os meninos acompanham os pais no trabalho com o gado ou na caça e pesca. Notamos que uma característica muito importante nessa população é o respeito com que ocorre esse processo, pois os pais indígenas não gritam com a criança, não batem, e, sim, conversam muito, tendo neste instrumento da linguagem, tanto corporal quanto verbal, o principal recurso para a educação de seus filhos, o que denota grande diferença para nossa população não-índia em relação à educação infantil.

No grupo terena de Córrego do Meio ocorreram informações nas entrevistas sobre modificações relevantes no sistema social e educação. Como exemplo dessas informações, uma das mães entrevistadas comentou que seus filhos não eram desobedientes. Relatou que na aldeia geralmente as crianças ficavam perto das mães e só não andavam mais junto aos pais quando ficavam adolescentes e, então, não precisavam mais obedecer.

Informou que seus filhos a obedeciam mais porque era ela que estava sempre presente, e se as crianças desobedeciam, ela conversava, mas na segunda vez, se não atendiam, acabavam levando umas palmadas ou umas "varinhadas" com vara verde. Quando perguntada sobre o que as crianças costumam fazer de errado, citou que geralmente subiam em árvores.

Eles não são desobedientes [...] sempre estão perto dos pais, só não ficam mais perto quando crescem, ficam adolescentes [...] aí não obedecem mais". "Eles obedecem mais en do que o pai, porque eles ficam mais comigo [...] quando não quer obedecer eu falo mais uma vez que não pode e se mais uma vez ela desobedecer en dou umas palmadas on umas varinhadas. (Família 1)

Eles não costumam desobedecer [...] eu costumo conversar, explico o que é errado, arrumo uma varinha verde e falo que se fižer de novo você vai 
apanhar. Depois se ela for além eu dou umas três varinbadas nela, quando ela acalma eu dou banbo nela para ela acalmar e pergunto para ela se ela sabe por que está apanbando. Não sei se é errado!Aqui é a mãe que cuida dos filhos, o pai trabalha na roça [...] eles têm mais respeito com o pai. (Família 2) ${ }^{3}$

Assim, nos trabalhos realizados nesse grupo encontramos pela primeira vez alguns relatos sobre sistemas de educação com punições semelhantes as que encontramos entre os não-índios.

\section{CONCLUSÕES}

Refletindo sobre educação infantil das populações indígenas estudadas, percebemos uma significativa diferença em comparação com a sociedade nacional na organização familiar e consequentemente, no acompanhamento das crianças nos primeiros anos de vida. A mãe que ainda pode ficar mais próxima dos filhos e outros membros da família, pela existência da grande família, contribui para a transmissão de costumes, crenças, padrões morais e éticos. Percebemos no referencial teórico e trabalhos de campo, em especial dos guarani, com uma bibliografia mais vasta sobre sua cultura e organização social, que a grande família tem um papel ativo e muito importante na educação e aprendizagem das crianças. A criança tem liberdade para participar livremente do cotidiano familiar, seus eventos, muitas vezes acompanhando os pais no seu trabalho doméstico ou na reserva.

$\mathrm{Na}$ sociedade nacional, de um modo geral, os filhos que antes eram deixados aos cuidados das mães passaram a frequentar as escolinhas, creches e escolas maternais, na presença das babás ou mesmo sozinhos em casa, brincando com games, televisores e computadores, ou quando não, apenas na rua brincando aqui ou ali com outras crianças, enquanto os pais não voltam do trabalho. Geralmente não residem com avós, tios, como acontecia antigamente na chamada grande familia.

Além disso, os pais de volta ao lar, já cansados pelo desgaste diário, nem sempre ou raramente têm paciência para conversar com a criança, explicar algo até que ela entenda. Algumas vezes acontece que em meio a gritos a mãe solicita alguma coisa à criança ou parte para a agressão física. Assim, a relação mãe $x$ filho nas populações não-índias difere muito das indígenas, pois nesta última as crianças recebem, na maioria das situações, mais carinho, respeito e atenção de seus familiares.

\footnotetext{
${ }^{3}$ Integrante do grupo de pesquisa com crianças Terena, Cabrera (2006: 59).
}

Cabe ressaltar que nos grupos indígenas em questão notamos que a criança tem um acompanhamento com conselhos, diálogo constante, acompanhada de liberdade para observar os adultos e participar de diferentes atividades na comunidade. A adolescência nesses grupos é um período mais curto ou praticamente é apenas uma espera para os rituais de iniciação do jovem, que logo ingressa na vida adulta, já com vivências e conhecimentos adquiridos na infância, muito diferente daquilo que acontece na sociedade nacional, onde referido período é cada vez mais longo e complexo até a pessoa atingir a idade adulta.

Neste estudo constatamos que mesmo em reservas com uma grande complexidade de problemas sociais, políticos e econômicos, como é a reserva de Dourados, a maneira como a criança indígena é educada na primeira socialização na família a que pertence, ou seja, na socialização primária, difere muito das crianças não-índias. Este fator pode ser o mais importante ou determinante para que essas crianças se ajustem com mais facilidade ao ambiente escolar, ou seja, na socialização secundária e o quanto este aspecto difere do comportamento escolar em relação às crianças na sociedade nacional.

Os terena de Córrego do Meio já apresentam situações diferenciadas das duas outras etnias, com eventuais punições na educação das crianças, na comunidade estudada, além de indicações de que a grande família vem dando lugar a um pequeno grupo constituído pelos pais e filhos.

As pesquisas sobre relações familiares nas sociedades indígenas podem e têm muito a contribuir com a sociedade não-índia, porém, fica uma indagação a ser respondida por aqueles que trabalham com a questão indígena: o que fazer para que os aspectos culturais evidenciados nestas pesquisas sejam preservados e também sirvam de modelo para toda a sociedade não-índia?

\section{REFERÊNCIAS}

Berger, L. \& Luckmann, T. (1985). A construção social da realidade: tratado de sociologia do conhecimento. Petrópolis-RJ: Vozes.

Cabrera, D. S. P. (2006). Cotidiano das familias Terena: um estudo exploratório. (Dissertação de Mestrado). Campo Grande-MS: Universidade Católica Dom Bosco.

Ferreira, M. S. (2007). Investigando os rumos da disciplina escolar Ciências no Colégio Pedro II: 1960-1970. Educ. ver,45, 127-144.

Grubits, S., Darrault-Harris, I. (2003). Ambiente, identidade e cultura: reflexões sobre comunidades Guarani/Kaiowá e Kadiwéu de Mato Grosso do Sul. Psicologia \& Sociedade, 1 (15), 182-200. 
Grubits, S., Darrault-Harris, I. (2001). Psicossemiótica na construção da identidade infantil: um estudo da produção artística de crianças Guarani/Kaiowá. São Paulo: Casa do Psicólogo; Campo Grande: Universidade Católica Dom Bosco.

Hutz, C. S. (Org.). (2005). Situações de risco e vulnerabilidade: pesquisa e intervenção. São Paulo: Casa do Psicólogo.

Ladeira, M., E., Azanha, G. Cosmologia e Xamanismo, 2004. Disponível em: <http:// pib.socioambiental.org/pt/povo/terena/1045> Acesso em 26 de fevereiro de 2009, 21:50.

Lino, A. R. S. (2006). A influência das relações familiares no ajustamento escolar da criança Kaiowá. (Dissertação de Mestrado). Campo Grande-MS: Universidade Católica Dom Bosco.

López, F. (1995). Desenvolvimento social e da personalidade. Em: Coll, C., Palacios, J. \& Marchesi, Á. (Org.). Desenvolvimento Psicológico e Educasãa. Psicologia Evolutiva. Porto Alegre: Artes Médicas. v.1.

Mangolim, Olívio (1999). Da escola que o branco faz à escola que o indio necessita e quer: uma educação indígena de qualidade. (Dissertação de Mestrado). Campo Grande-MS: Universidade Católica Dom Bosco.
Meliá, B. (1979). Educação indígena e alfabetização. São Paulo: Loyola.

Rego, T. C. R. (1996). A indisciplina e o processo educativo: uma análise na perspectiva vygotskiana. Em: Aquino, G. J. (Org.). Indisciplina na escola: alternativas teóricas e práticas. São Paulo: Summus Editorial, 83-101.

Reis, J. R. T. (1984). Família emoção e ideologia. Em: Lane, S. T. M. Psicologia Social: o homem em movimento. São Paulo: Brasiliense, 99-124.

Schaden, E. (1974). Aspectos Fundamentais da Cultura Guarani. São Paulo: EPU, Ed da Universidade de São Paulo.

Siqueira Jr., J. G. (1987). Arte e Técnicas Kadiwéu. São Paulo: Prefeitura de São Paulo.

Vigotsky, L. S. (1987). A formacão social da mente. São Paulo: Martins Fontes.

Viveiros de Castro, Eduardo B. (1986). Araweté, os deuses canibais. (Tese de Doutorado). Rio de Janeiro: da Universidade Federal do Rio de Janeiro - Programa de Pós Graduação em Antropologia Social do Museu Nacional.

Recebido em setembro de 2008

Reformulado em abril de 2009

Aprovado maiode 2009

\section{Sobre os autores:}

Sonia Grubits, Doutora com status de pós-doutora em Semiótica por Paris 8 - Sorbonne, França, pós doutora e doutora em Saúde Mental pela Faculdade de Ciências Médicas da UNICAMP, Mestrado em Psicologia Social pela PUCSP, Psicóloga pela PUCRJ. Formada em Comunicações pela UFRJ, professora, pesquisadora e coordenadora do Programa de Mestrado em Psicologia da Universidade Católica Dom Bosco, UCDB, MS, Brasil e bolsista de produtividade pesquisa do CNPq. E-mail: sgrubits@uol.com.br. Av. Mato Grosso, n. 759, Centro, Campo Grande/MS, Brasil, Cep 79002 - 231, Tel./Fax: (55) (67) 33823631

Heloisa Bruna Grubits Freire, Doutora em Saúde Mental pela Faculdade de Ciências Médicas da UNICAMP, mestre em Psicologia, psicóloga pela UCDB, professora, pesquisadora do Programa de Mestrado em Psicologia da Universidade Católica Dom Bosco, MS, Brasil. E-mail: freirejb@terra.com.br. Av. Mato Grosso, n. 759, Centro, Campo Grande/MS, Brasil, Cep 79002 - 231, Tel./Fax: (55) (67) 33823631

José Angel Vera Noriega, Professor pesquisador na área de Desenvolvimento Regional, Centro de Investigação em Alimentação e Desenvolvimento A.C., México. E-mail: avera@cascabel.ciad.mx. Apartado Postal 1735, Carretera a la Victoria km. 0.6, Hermosillo, Sonora, México. C.P.83000, Tel.: (662) 289 - 24 - 00 Ext. 317, Fax: (662) $280-00-55$. 